\title{
The Association Between Gallstone Disease and Metabolic Syndrome Related Abnormalities: A Systematic Review and Meta- Analysis
}

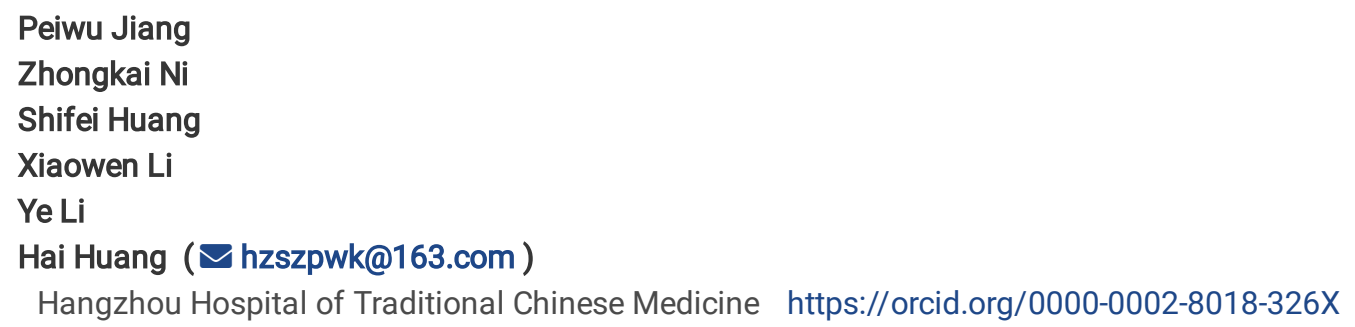

Peiwu Jiang

Zhongkai Ni

Shifei Huang

Xiaowen Li

Ye Li

Hai Huang ( $\nabla$ hzszpwk@163.com )

Hangzhou Hospital of Traditional Chinese Medicine https://orcid.org/0000-0002-8018-326X

\section{Research}

Keywords: metabolic syndrome, gallstone disease, insulin resistance, meta-analysis

Posted Date: February 19th, 2020

DOI: https://doi.org/10.21203/rs.2.23967/v1

License: @ (i) This work is licensed under a Creative Commons Attribution 4.0 International License. Read Full License

Version of Record: A version of this preprint was published at International Journal of Diabetes in Developing Countries on November 28th, 2020. See the published version at https://doi.org/10.1007/s13410-020-00890-9. 


\section{Abstract}

\section{Background}

Bile excretion is one of an important metabolite excretion pathway of human body. In recent years, it has been reported that metabolic diseases are associated with the occurrence of GSD (Gallstone Disease). The main purpose of this systematic review is to examine the relationship between metabolic syndrome and cholelithiasis, including components of the metabolic syndrome such as abnormal blood glucose regulation, hyperlipidemia, and obesity.

\section{Methods}

Pubmed, Cochrane library and embase were searched for all English language articles for the following relevant keywords: Metabolic Syndrome, Reaven Syndrome X, Biliary Calculi, Cholelithiasis Gallstones. Case-control study, cross-sectional study and cohort study were included .Pooled relative risks (RRs) or odds ratios (ORs) and their corresponding 95\% confidence intervals (Cls) were calculated. The pooled mean differences of the outcome measures were compared between patients with and without MetS.

\section{Results}

After screening, a total of 5 cross-sectional studies and 1 cohort studies were included in the meta-analysis. The 6 studies evaluated a total of 49101 people『of whom 9055 had MS and 2308 had GSD. There is a significant correlation between MS and GSD ( $z=6.65, p=$ 0.000), and it's more significant in female. All studies displayed increasing odds of GSD with increasing number of MetS traits, where patients with three or more MetS traits tended to have a higher prevalence of nephrolithiasis.

\section{Conclusions}

Our review shows a definite association of MetS with GSD, and the more the components of MetS, the higher the prevalence of GSD. Although not as obvious as women, men also support this conclusion.

\section{Background}

Gallstones disease (GSD) are the most common digestive disease needing admission to hospital in the West. With a prevalence of 10$15 \%$ in adults in Europe and the USA, $5-20 \%$ in Asian populations gallstone disease is one of the most common and most expensive to treat of digestive disorders that need admission to hospital[1-4]. It constituting a major health burden that has increased more than $20 \%$ over the last 3 decades in the US[5].

Gallstones are a disease that is more common in female than in male[6]. Risk factors include gender, obesity, and chronic liver diseases such as fatty liver, cirrhosis, and gastrectomy. Patients such as diabetes are also susceptible to gallstone disease[7].

Metabolic syndrome (MetS) is a state in which multiple metabolic risk factors for cardiovascular disease build up within an individual [8]. The main components of MetS are obesity, especially visceral obesity, diabetes, or impaired glucose regulation, hypertension and lipid disorders which are characterized by hypertriglyceridemia (TG) and low-density lipoprotein cholesterol (HDL-C). In addition, MS also includes tissue insulin resistance, hyperuricemia, and microalbuminuria that reflects vascular endothelial cell dysfunction.[9, 10]. The prevalence of metabolic syndrome has increased dramatically worldwide[8, 11, 12]. Studies about the association between gallstone disease and MetS suggested that MetS is a risk factor for gallstone disease[13]. Most of key components for the diagnosis of MetS are also key risk factors of GSD[9]. As a whole, metabolic syndrome is also associated with cholelithiasis, the purpose of this meta-analysis was to examine the association of MS and gallstones integrated and independent by component.

\section{Methods}

\section{Search Strategy and Selection Criteria}

This systematic review and meta-analysis was performed in accordance with MOOSE guidelines[14]. The major medical databases in the English language, among which were Cochrane, EMBASE, PUBMED were searched up to September 15, 2019 , using the following keywords in combination with both medical subject heading terms and text words: "Metabolic Syndrome X," "Metabolic syndrome," "Insulin Resistance Syndrome X," "Reaven Syndrome X," "Cholecystolithiasis," "Cholelithiasis," “Choledocholithiasis," "Biliary Calculi," and "Gallstones." 


\section{Study selection and data extraction}

Two reviewers independently screened all the titles and abstracts in an effort to minimize selection bias, and a third reviewer was consulted for resolution of disagreements. The following information was extracted from all the literatures: research design type, region, number of patients included, diagnostic methods of cholelithiasis, diagnostic criteria of metabolic syndrome, BMI (Body Mass Index), age, incidence of metabolic syndrome and its components such as waist circumference, blood pressure (systolic pressure, diastolic pressure), fasting blood glucose, LDL-C, TG (Triglyceride) and other blood biochemical indicators in cholelithiasis group and control group. For continuous data (such as age, blood pressure, fasting blood glucose, etc.), mean + SD and the number of people in the group were extracted respectively. For count data (such as hypertension and diabetes mellitus), the corresponding number of people in the two groups and the total number of people in the group were extracted respectively.

Studies were included if the following criteria were met: 1. Retrospective or prospective cohort study, cross-sectional study, case-control study. 2. The experimental group met the diagnostic criteria for MetS 3. The diagnosis of cholelithiasis was confirmed by imaging evidence or surgical evidence. 4. The control group was included in the study and odds ratios (ORs) in case-control studies or relative risks (RR) in cohort studies were reported with the $95 \%$ confidence intervals (Cls) (or, if 95\% Cls were not reported, the reported data were sufficient to calculate them). Studies were excluded if: 1. Literature was not the above research type, or the unpublished. 2. The study did not set up a control, or the number of cases less than 10, patients with long-term use of drugs proved to be conducive to stone formation or stone discharge. 3. The patients in the study had organic lesions, liver dysfunction or viral hepatitis in the hepatobiliary system. 4 . Only the latest research involving more cases included in from the similar study of the same authors.

\section{Quality Assessment}

The Newcastle-Ottawa scale was used to assess the quality of the included studies[15]. Briefly, the instrument contains 8 items categorized into 3 dimensions: the selection of the study groups; the comparability of the groups; and the ascertainment of either the exposure or outcome of interest for case-control or cohort studies respectively. An 8-point scoring system is used for a semiquantitative assessment of study quality, score of 5-8 were classified as qualified studies [16]. Cross sectional studies use the quality evaluation criteria recommended by AHRQ (Agency for Healthcare Research and Quality, which includes eleven items. Article quality was assessed as follows: low quality = 0-3; moderate quality $=4-7$; high quality $=8-11[17]$.

\section{Outcome Measures and Data Analysis}

The primary outcome was the correlation between the incidence of cholelithiasis with metabolic syndrome patients and that in nonmetabolic syndrome patients, and the incidence of cholelithiasis in different sexes, the relationship between the components of metabolic syndrome and the incidence of cholelithiasis, and the relationship of number of components of metabolic syndrome and cholelithiasis. The effect measures of interest were odds ratios for case-control studies and cross sectional studies, relative risks for cohort studies, and the corresponding $95 \%$ confidence intervals are given.

The heterogeneity of the study was evaluated by $I^{2}$ statistics. The $I^{2}>50 \%$ was taken to indicate high levels of heterogeneity and the random effect analysis modelis used. Otherwise, the fixed effect model will be used. Subgroup analysis was performed to explore potential heterogeneity. A P value $<0.05$ was considered statistically significant, and $95 \%$ confidence intervals (Cls) are given. The metaanalyses were performed using Stata software (version 14; Stata Corp, College Station, TX). The Z test was used to examine differences in experiment group and control group. A Z value more than 1.96 and $p<0.05$ was considered statistically significant, and the $95 \%$ confidence intervals $(\mathrm{Cls})$ are given.

\section{Result}

A flow diagram of study selection is shown in Fig. 1. After the initial literature searching and eliminating duplicate articles, 94 were excluded from 432 identified articles (Fig. 1). 319 unrelated articles and reviews were excluded after examination. Careful reading of the full text and excluded the inconsistency of research type or purpose, and finally 6 articles were included in the study $[6,13,18-21]$

including 5 cross-sectional studies and 1 cohort study. We found no related or relevant meta-analyses in the Cochrane library. A summary of the 6 included studies is given in Table 1. The 6 studies included in the meta-analysis contained a total of 48858 people, wherein 5451 had MetS and 43407 did not have MetS. 
Table 1

Characteristics of 6 studies included into present meta-analysis.

\begin{tabular}{|c|c|c|c|c|c|c|c|c|}
\hline \multicolumn{9}{|c|}{ Basic Characteristics of Included Studies } \\
\hline Study(year) & Country/Area & $\begin{array}{l}\text { Sample } \\
\text { Size }\end{array}$ & Definition of MetS & $\begin{array}{l}\text { Imaging } \\
\text { Technique }\end{array}$ & $\begin{array}{l}\text { Blind } \\
\text { Method }\end{array}$ & $\begin{array}{l}\text { Study } \\
\text { Design }\end{array}$ & $\begin{array}{l}\text { Quality } \\
\text { Evaluation } \\
\text { Method }\end{array}$ & Score \\
\hline Tsai,2009 & $\begin{array}{l}\text { Taiwan, } \\
\text { China }\end{array}$ & 8188 & NCEP-ATPIII & ultrasonography & $\begin{array}{l}\text { double } \\
\text { blind }\end{array}$ & $\begin{array}{l}\text { Cross } \\
\text { sectional }\end{array}$ & AHRQ & 8 \\
\hline Lin,2012 & $\begin{array}{l}\text { Taiwan, } \\
\text { China }\end{array}$ & 11527 & NCEP-ATPIII & ultrasonography & $\begin{array}{l}\text { double } \\
\text { blind }\end{array}$ & $\begin{array}{l}\text { Cross } \\
\text { sectional }\end{array}$ & AHRQ & 8 \\
\hline Zhu, 2010 & China & 18291 & CDS & ultrasonography & $\begin{array}{l}\text { double } \\
\text { blind }\end{array}$ & Cohort & NOS & 6 \\
\hline $\begin{array}{l}\text { Méndez- } \\
\text { Sánchez,2005 }\end{array}$ & Mexico & 245 & NCEP-ATPIII & ultrasonography & $\begin{array}{l}\text { double } \\
\text { blind }\end{array}$ & $\begin{array}{l}\text { Cross } \\
\text { sectional }\end{array}$ & AHRQ & 5 \\
\hline Chen,2012 & China & 7570 & NCEP-ATPIII & ultrasonography & $\begin{array}{l}\text { double } \\
\text { blind }\end{array}$ & $\begin{array}{l}\text { Cross } \\
\text { sectional }\end{array}$ & AHRQ & 9 \\
\hline $\begin{array}{l}\text { Shabanzadeha, } \\
2017\end{array}$ & Denmark & 2650 & IDF,AHA/NHLBI,2009 & ultrasonography & $\begin{array}{l}\text { double } \\
\text { blind }\end{array}$ & $\begin{array}{l}\text { Cross } \\
\text { sectional }\end{array}$ & AHRQ & 8 \\
\hline
\end{tabular}

\section{Primary Outcome}

The main findings of the study were the incidence of cholelithiasis in MetS and Non-MetS populations. In the six studies included, significant heterogeneity was observed. Heterogeneity chi-squared $=18.69$ (d.f.= 5), p = 0.002,I-squared (variation in RR attributable to heterogeneity) $=73.2 \%$, and thus a random-effects model of analysis was performed. Estimate of between-study variance Tau-squared = 0.0213 Test of $R R=1: z=6.65 \varangle 2.58, p=0.000$. The result indicate that patients with MetS had a significantly higher GSD incidence than patients without MS.

A subgroup analysis was conducted to investigate people from different regions lead to strong heterogeneity. Four and two studies were included in the analysis of the associations between Asia and Europe\& America countries in the incidence of GSD (Fig. 3). The pooled estimates indicated that neither Asia populations ( $p=0.007$, I-squared $=75.4 \%)$ nor Europe $\&$ America $(p=0.026, I$-squared $=79.9 \%)$ populations contribute to the heterogeneity of incidence of cholelithiasis in MetS and Non-MetS populations.

An analysis was also conducted to investigate the effect of gender on the incidence of GSD between MetS populations and non-MetS. Three studies reported the gender data were included (Fig. 4.). Significant heterogeneity was observed in male patient $\left(p=0.030, I^{2}=\right.$ $71.5 \%)$ and overall patient $\left(p=0.000, l^{2=} 78.5 \%\right)$, and thus a random-effects model of analysis was performed. Male patients $(z=10.22, p=$ $0.000)$ and female patients $(z=8.45, p=0.000)$ and overall patients $(z=12.45, p=0.000)$ with MS have more rate for gallstone disease than without MS.

Four studies reported age data (Fig. 5). No significant heterogeneity was observed (Heterogeneity chi-squared $=5.82, p=0.121, \mathrm{I}$-squared $=$ $48.5 \%)$, and thus a fix-effects model of analysis was performed. We found old patients $(z=21.16 p=0.000)$ have higher incidence for gallstone disease than the youngers.

Four studies reported BMI data (Fig. 6). Significant heterogeneity was observed (Heterogeneity chi-squared $=12.19, \mathrm{p}=0.007, \mathrm{I}$-squared $=$ $75.4 \%$ ) and thus a random-effects model of analysis was performed. Patients with high BMI are more likely to suffer from GSD ( $\mathrm{z}=5.74$ $p=0.000)$.

Four studies reported WC (waist circumference) data (Fig. 7). Significant heterogeneity was observed (Heterogeneity chi-squared = 11.23, $p=0.011$, l-squared $=73.3 \%$ ) and thus a random-effects model of analysis was performed. Patients with high WC are more likely to get GSD $(z=6.57, p=0.000)$.

Four studies reported TC (Total Cholesterol) data (Fig. 8). Significant heterogeneity was observed (Heterogeneity chi-squared = 8.44, $\mathrm{p}=$ 0.015 , l-squared $=76.3 \%$ ) and thus a random-effects model of analysis was performed. There was no significant difference in two groups of people $(z=0.66, p=0.508)$ indicating that there was no significant increase in the incidence of cholelithiasis among people with higher TC levels. 
Four studies reported FPG (Fasting Plasma Glucose) data (Fig. 9). Significant heterogeneity was observed (Heterogeneity chi-squared = $7.41, \mathrm{P}=0.060$; I-squared $=59.5 \%$ ) and thus a random-effects model of analysis was performed. Patients with high FPG develop GSD more often than men $(z=5.23, p=0.000)$.

Table 2

The prevalence of gallstone in subjects with different numbers of metabolic abnormalities.

\begin{tabular}{|llllll|}
\hline Cochran-Armitage Test for Trend & \multicolumn{3}{l|}{} \\
\hline Number of metabolic abnormality & Number yes & Number no & Number total & Prevalence & Test for trend \\
\hline 0 & 283 & 8308 & 8591 & 3.29 & Pø0.0001 \\
\hline 1 & 377 & 7537 & 7914 & 4.76 & Z $=12.3032$ \\
\hline 2 & 394 & 5660 & 6054 & 6.51 & 7.95 \\
\hline$\geq 3$ & 331 & 3834 & 4165 & \\
\hline
\end{tabular}

With regard the number of components and the incidence of GSD, we merge data from three articles,participants were divided into 4 levels according to the counts of their metabolic disorders. Cochran-Armitage Test for Trend were used in the SAS system (version9.2). Among the subjects with different numbers of metabolic abnormalities, there was an increased prevalence of gallstones as the number of metabolic abnormalities increased (test for trend, pष0.001, Table 2). Even if the diagnostic criteria for MS are not met, the independent component remains a risk factor for GSD, and as the number increases, the risk of GSD increases.

\section{Discussion}

Gallstones can be divided into the following types: cholesterol stones, pigment stones, and mixed stones. Cholesterol stones must be at least $80 \%$ cholesterol by weight. Other common constituents are primarily of bilirubin (insoluble bilirubin pigment polymer) and calcium (calcium phosphate) salts that are found in bile.Between $35 \%$ and $90 \%$ of stones are cholesterol stones[22]. During the formation of cholesterol stones, impaired motility of gallbladder smooth muscle (GBSM), increased residual volume of fasting gallbladder and decreased contractility play an important role[23-25]. Long bile retention time in gallbladder may lead to high concentration in gallbladder bile and promote cholesterol precipitation in epithelial cells[26]. Occasionally chronic bacterial infections, although asymptomatic, can also be a cause of $\operatorname{GSD}[27,28]$.

Metabolic syndrome was first proposed by Reaven in 1993, which was then called X syndrome[29]. The main clinical manifestations were insulin resistance (IR), hyperinsulinemia, impaired glucose tolerance (IGT), hypertension and abnormal atherogenic lipid metabolism[30]. Different definitions of MetS have been proposed, reviewed, recommended, and even questioned over the decades., the World Health Organization (WHO) first proposed a working definition centering on IR or hyperglycemia[31]. The National Cholesterol Education Program's Adult Treatment Panel III (NCEP ATP III) of the United States proposed diagnostic criteria for MS in 2001[32].

In the past 20 years, the national choreol education program's Adult Treatment Panel III (NCEP ATP III) of the United States and IDF have proposed new definitions successively, but they have these core components including central observatory, dyslipidemia, hypertention, and insulin resistance. In fact, it also proved to be reliable and universally accepted diagnostic tool.[33-35].

This study aimed to evaluate the association of MS with characteristics of gallstone. The results showed that The incidence of gallstones in MetS patients is increased compared with patients without MetS. A subgroup analysis by sex analysis showed that both men and women had an increased incidence. Analysis of various factors including MS components, the incidence of cholelithiasis increased in older patients, obesity-related factors, high blood lipids TC, WC, BMI were positively correlated with the incidence of cholelithiasis, fasting blood glucose Diabetes and hypertension are also positively correlated with the incidence of cholelithiasis. In male subjects, metabolic syndrome was associated with presence of gallstones, and the size of gallstones[36].

In recent years, insulin resistance is another hot topic among metabolic abnormalities associated with GSD. Not only obese people, insulin resistance can be also occur in people with normal weight. A study in a Hispanic population found that GS was associated with insulin resistance, fatty liver and metabolic syndrome. Insulin resistance is a risk factor for GS[37]. Insulin resistance may play an important role in the pathogenesis of GS favoring the production of cholesterol supersaturated bile and altering gallbladder function[37]. Nakeeb et al. [38] demonstrated that insulin resistance alone may be responsible for gallbladder dysmotility, which may result in acalculous cholecystitis or gallstone formation. 
Even have evidence supports the contention that insulin resistance not only directly induce gallbladder inflammation increase mucus production and alter gallbladder function, but could also favors the secretion by the liver of cholesterol supersaturated bile[39]. The latter seems more accepted pathogenic link. GS increase of cholesterol saturation in gallbladder bile, a phenomenon related to increase of body cholesterol synthesis and hypersecretion of biliary cholesterol as observed in obesity[28].Park et al. stated that adiponectin acted as a critical element in the development of insulin resistance, the lower the rate of obesity, weight, and BMI, the higher the concentration of adiponectin and that this information would be helpful for the treatment of diabetes[40].

The definition presented by the IDF that emphasizes abdominal obesity as a sine qua non diagnostic factor [47]. In fact, it has been confirmed that some indicators such as larger waist circumference, higher BMI and hyperlipidemia are obese manifestations. Recent data from animal and human studies have shown that the gallbladder of obese people is enlarged and their response to neurotransmitters is usually reduced. A high-fat diet can lead to abnormal emptying of the gallbladder. Drugs that inhibit the absorption of lipids, normalize gallladder function, and prevent cholesteric crystal and gallstone formation[41]. In addition, obese and high carbohydrate diet had increased gallbladder tissue levels of tumor necrosis factor-alpha, interleukin- 6 and interleukin- 1 beta. These changes lead to decreased smooth muscle function and diminished gallbladder absorption [41].

The function of bile components secretory also increased in GS patients. In a study from Chile, increased bile synthesis was found in GS patients [42]. In terms of direct bilirubin, also normal mean values for total bilirubin ( $15.96 \pm 5.23 \mu \mathrm{mol} / \mathrm{L})$, but pathological ones for direct bilirubin $(7.78 \pm 5.41 \mu \mathrm{mol} / \mathrm{L})$, as well as the modification of the normal subunit direct to indirect bilirubin ratio, in the sense of the equalization, only in the group with metabolic syndrome and gallstones.

Although there is no parallel relationship with blood lipids level, increased lipid components excretion through bile directly promote the formation of cholesterol stones. Total cholesterol, direct bilirubin and especially lean body weight might provide simple stratification tools for obese women, outlining a high risk profile for developing gallstones[43].

\section{Conclusions}

Despite some heterogeneity is generated which perhaps due to the different diagnostic criteria of metabolic syndrome or some other errors, However, the trend of results shows that metabolic syndrome is closely related to cholelithiasis. Even some researchers propose that GD is another member of the metabolic syndrome[44]. These results also suggest that the metabolic syndrome can even be regarded as another indication for prophylactic surgery in patients with GSD.

\section{Declarations}

\section{Funding}

The authors received no specific funding for this work.

\section{Conflict of Interest}

The authors have no other conflicts of interest.

\section{Ethics approval}

Not applicable

\section{Consent to participate}

Not applicable

\section{Consent for publication}

Not applicable

\section{Availability of data and material}

Not applicable

\section{Code availability}


Not applicable

\section{Authors' contributions}

$\mathrm{PJ}$ and $\mathrm{HH}$ conceived and designed the study. ZN and $\mathrm{XL}$ performed the experiments. PJ and DL wrote the paper. PJ, ZN, XL, YL and HH reviewed and edited the manuscript. All authors read and approved the manuscript.

\section{References}

1. Portincasa, Piero, Antonio Moschetta, and Giuseppe Palasciano. 2006. Cholesterol gallstone disease. Lancet 368 (9531):230.

2. Everhart, James E., Meena Khare, Michael Hill, and Kurt R. Maurer. 1999. Prevalence and ethnic differences in gallbladder disease in the United States. Gastroenterology 117 (3):632-639.

3. Sandler, Robert S., James E. Everhart, Mark Donowitz, Elizabeth Adams, Kelly Cronin, Clifford Goodman, Eric Gemmen, Shefali Shah, Aida Avdic, and Robert Rubin. 2002. The burden of selected digestive diseases in the United States $\mathbb{\square}$ 《. Gastroenterology 122 (5):1500-1511.

4. Shaffer, Eldon A. 2006. Epidemiology of gallbladder stone disease. Best Practice \& Research Clinical Gastroenterology 20 (6):981-996.

5. LM, Stinton, and Shaffer EA. 2012. Epidemiology of gallbladder disease: cholelithiasis and cancer. Gut and Liver 6 (2):172-187.

6. Lin, I Ching, Yu Wen Yang, Mei Feng Wu, Yi Hui Yeh, Jenn Chang Liou, Ying Li Lin, and Chih Hsiang Chiang. 2014. The association of metabolic syndrome and its factors with gallstone disease. Bmc Family Practice 15 (1):138.

7. Stinton, Laura M., and Eldon A. Shaffer. 2012. Epidemiology of Gallbladder Disease: Cholelithiasis and Cancer. Gut \& Liver 6 (2):172187.

8. Aguilar, M., T. Bhuket, S. Torres, B. Liu, and R. J. Wong. 2015. Prevalence of the metabolic syndrome in the United States, $2003-2012$. Jama 313 (19):1973-1974. doi:10.1001/jama.2015.4260.

9. Alberti, K. G., R. H. Eckel, S. M. Grundy, P. Z. Zimmet, J. I. Cleeman, K. A. Donato, J. C. Fruchart, W. P. James, C. M. Loria, and S. C. Smith, Jr. 2009. Harmonizing the metabolic syndrome: a joint interim statement of the International Diabetes Federation Task Force on Epidemiology and Prevention; National Heart, Lung, and Blood Institute; American Heart Association; World Heart Federation; International Atherosclerosis Society; and International Association for the Study of Obesity. Circulation 120 (16):1640-1645. doi:10.1161/circulationaha.109.192644.

10. Grundy, S. M., James Cleeman, S. R. Daniels, Karen Donato, Robert Eckel, and B. A. Franklin. 2005. Diagnosis and management of the metabolic syndrome: An American Heart Association/National Heart, Lung, and Blood Institute Scientific Statement.

11. Kim, Hyun Ja, Yuna Kim, Yumi Cho, Byungyool Jun, and Kyung Won Oh. 2014. Trends in the prevalence of major cardiovascular disease risk factors among Korean adults: Results from the Korea National Health and Nutrition Examination Survey, 1998\&\#x2013;2012. International Journal of Cardiology 174 (1):64-72. doi:10.1016/j.ijcard.2014.03.163.

12. Li, Y., L. Zhao, D. Yu, Z. Wang, and G. Ding. 2018. Metabolic syndrome prevalence and its risk factors among adults in China: A nationally representative cross-sectional study. Plos One 13 (6):e0199293.

13. Méndezsánchez, N, N. C. Chaveztapia, D Motolakuba, K Sanchezlara, G Poncianorodríguez, H Baptista, M. H. Ramos, and M Uribe. 2005. Metabolic syndrome as a risk factor for gallstone disease. World Journal of Gastroenterology 11 (11):1653-1657.

14. Stroup, D. F., J. A. Berlin, S. C. Morton, I. Olkin, G. D. Williamson, D. Rennie, D. Moher, B. J. Becker, T. A. Sipe, and S. B. Thacker. 2000. Meta-analysis of observational studies in epidemiology: a proposal for reporting. Meta-analysis Of Observational Studies in Epidemiology (MOOSE) group. Jama 283 (15):2008-2012.

15. Wells, GA, B Shea, D O'Connell, J Peterson, V Welch, M Losos, and P Tugwell. 2015. The Newcastle-Ottawa Scale (NOS) for assessing the quality of nonrandomised studies in meta-analysis. http://www.ohri.ca/programs/clinical_epidemiology/oxford.asp. . Accessed.

16. Zeng, X., Y. Zhang, J. S. Kwong, C. Zhang, S. Li, F. Sun, Y. Niu, and L. Du. 2015. The methodological quality assessment tools for preclinical and clinical studies, systematic review and meta-analysis, and clinical practice guideline: a systematic review. J Evid Based Med 8 (1):2-10. doi:10.1111/jebm.12141.

17. Sanderson, Simon, lain D Tatt, and Julian Pt Higgins. 2007. Tools for assessing quality and susceptibility to bias in observational studies in epidemiology: a systematic review and annotated bibliography. International Journal of Epidemiology 36 (3):666.

18. Shabanzadeh, Daniel Mønsted, Tea Skaaby, Lars Tue Sørensen, Jesper Eugenolsen, and Torben Jørgensen. 2017. Metabolic biomarkers and gallstone disease - a population-based study. Scand J Gastroenterol:1-8. 
19. Li-Ying, Chen, Qiao-Hua, Qiao, Shan-Chun, Zhang, Yu-Hao, Chen, Guan-Qun, and Chao. 2012. Metabolic syndrome and gallstone disease. World Journal of Gastroenterology Wjg 18 (31):4215.

20. Zhu, Qian, Xiubin Sun, Xiaokang Ji, Lin Zhu, Jing Xu, Chunxia Wang, Chengqi Zhang, Fuzhong Xue, and Yanxun Liu. 2016. The association between gallstones and metabolic syndrome in urban Han Chinese: a longitudinal cohort study. Scientific Reports 6:29937.

21. Chung-Hung, Tsai, Wu Jin-Shang, Chang Yin-Fan, Lu Feng-Hwa, Yang Yi-Ching, and Chang Chih-Jen. 2014. The number of metabolic abnormalities associated with the risk of gallstones in a non-diabetic population. Plos One 9 (3):e90310.

22. In Sook, Kim, Myung Seung-Jae, Lee Sang-Soo, Lee Sung-Koo, and Kim Myung-Hwan. 2003. Classification and nomenclature of gallstones revisited. Yonsei Medical Journal 44 (4):561-.

23. Fridhandler, T M, J S Davison, and E A Shaffer. 1983. Defective gallbladder contractility in the ground squirrel and prairie dog during the early stages of cholesterol gallstone formation. Gastroenterology 85 (4):830-836.

24. Portincasa, Piero, Agostino Di Ciaula, and Gerard P. Vanberge-Henegouwen. 2004. Smooth muscle function and dysfunction in gallbladder disease. Current Gastroenterology Reports 6 (2):151-162.

25. Kishk, S M, R M Darweesh, W J Dodds, T L Lawson, E T Stewart, M K Kern, and E H Hassanein. 1987. Sonographic evaluation of resting gallbladder volume and postprandial emptying in patients with gallstones. Ajr American Journal of Roentgenology 148 (5):875.

26. Yongsheng, Chen, Kong Jing, and Wu Shuodong. 2015. Cholesterol gallstone disease: focusing on the role of gallbladder. Laboratory investigation; a journal of technical methods and pathology 95 (2):124-131.

27. Yoosoo, Chang, Sung Eunju, Ryu Seungho, Park Yong-Woo, Jang Yu Mi, and Park Minseon. 2008. Insulin resistance is associated with gallstones even in non-obese, non-diabetic Korean men. Journal of Korean Medical Science 23 (4):644-650.

28. Shaffer, Eldon A. 2005. Epidemiology and risk factors for gallstone disease: has the paradigm changed in the 21 st century? Current Gastroenterology Reports 7 (2):132-140.

29. Reaven, Gerald M. 1993. Role of Insulin Resistance in Human Disease (Syndrome X): An Expanded Definition. Annual Review of Medicine 44 (1):121.

30. Samson, S. L., and A. J. Garber. 2014. Metabolic syndrome. Endocrinol Metab Clin North Am 43 (1):1-23. doi:10.1016/j.ecl.2013.09.009.

31. Balkau, B, and M. A. Charles. 2010. Comment on the provisional report from the WHO consultation. European Group for the Study of Insulin Resistance (EGIR). Diabet Med 16 (5):442-443.

32. Expert Panel on Detection, Evaluation. 2001. Executive Summary of The Third Report of The National Cholesterol Education Program (NCEP) Expert Panel on Detection, Evaluation, And Treatment of High Blood Cholesterol In Adults (Adult Treatment Panel III). Circulation 106 (25):3143-3421.

33. Sirdah, M. M., A. S. Abu Ghali, and N. A. Al Laham. 2012. The reliability of the National Cholesterol Education Program's Adult Treatment Panel III (NCEP/ATP III) and the International Diabetes Federation (IDF) definitions in diagnosing metabolic syndrome (MetS) among Gaza Strip Palestinians. Diabetes \& Metabolic Syndrome Clinical Research \& Reviews 6 (1):4-8.

34. Zimmet, P, DMatsuzawa Y Magliano, G Alberti, and J Shaw. 2005. The metabolic syndrome: a global public health problem and a new definition. Journal of Atherosclerosis \& Thrombosis 12 (6):295-300.

35. Alberti, K. G., P. Zimmet, and J. Shaw. 2005. The metabolic syndrome-a new worldwide definition. Lancet 366 (9491):1059-1062. doi:10.1016/s0140-6736(05)67402-8.

36. Sang, Jae Hong, Nam Kyun Ki, Jae Hwan Cho, Jae Ouk Ahn, and Jae Gun Sunwoo. 2016. Correlations between metabolic syndrome, serologic factors, and gallstones. Journal of Physical Therapy Science 28 (8):2337-2341.

37. Nervi, Flavio, Juan Francisco Miquel, Manuel Alvarez, Catterina Ferreccio, María José García-Zattera, Robinson González, Rosa María Pérez-Ayuso, Attilio Rigotti, and Luís Villarroel. 2006. Gallbladder disease is associated with insulin resistance in a high risk Hispanic population. Journal of Hepatology 45 (2):299-305.

38. Nakeeb, Attila, Anthony G. Comuzzie, Hayder Al-Azzawi, Gabriele E. Sonnenberg, Ahmed H. Kissebah, and Henry A. Pitt. 2006. Insulin Resistance Causes Human Gallbladder Dysmotility. Journal of Gastrointestinal Surgery 10 (7):940-949.

39. Twisk, Jaap, Marco F.M. Hoekman, Eline M. Lehmann, Piet Meijer, Willem H. Mager, and Hans M.G. Princen. 2010. Insulin suppresses bile acid synthesis in cultured rat hepatocytes by down-regulation of cholesterol 27-hydroxylase and sterol 7a-hydroxylase gene transcription. Hepatology 21 (2):501-510. 
40. Park, Jee Yoon, Su Jin Cho, Kyung Hyo Kim, Young Mi Hong, and Keun Lee. 2004. A Study for Adiponectin in Obese Adolescents with Hypertension. Korean Journal of Pediatrics (7).

41. Pitt, Henry A. 2007. Hepato-pancreato-biliary fat: the good, the bad and the ugly. HPB 9 (2):92-97.

42. Cecilia, G? Lman, Miquel Juan Francisco, Pérez Rosa Maria, Einarsson Curt, St?Hle Lars, Marshall Guillermo, Nervi Flavio, and Rudling Mats. 2004. Bile acid synthesis is increased in Chilean Hispanics with gallstones and in gallstone high-risk Mapuche Indians.

Gastroenterology 126 (3):741-748.

43. Cojocaru, Doina Clementina, Florin Mitu, Cristina Gena Dascălu, Alina Manole, and Corina Dima-Cozma. 2014. The predictors of cholelithiasis in female patients with metabolic syndrome. Central European Journal of Medicine 9 (1):108-114.

44. Grundy, Scott M. 2004. Cholesterol gallstones: a fellow traveler with metabolic syndrome? American Journal of Clinical Nutrition 80 $(1): 1-2$.

Figures

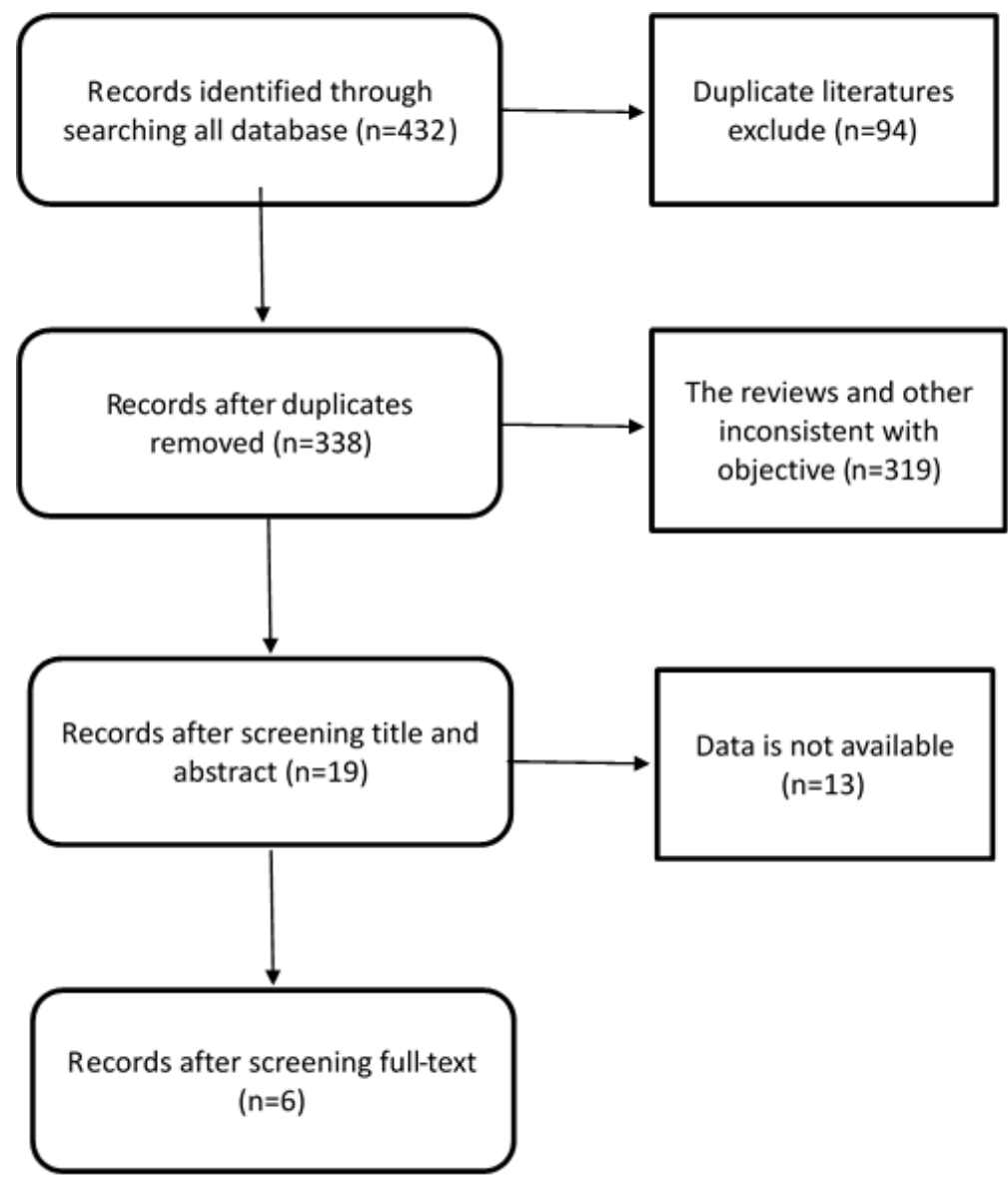

Figure 1

Flow diagram of the literature search in this meta-analysis. 
Study

ID

Tsai (2000)

Lin (2011)

Zhu (2005)

Méndez-Sánchez (2005)

Chen (2012)

Shabanzadeha (2017)

Overall $(1$-squared $=73.2 \%, p=0.002)$

NOTE: Weights are from random effects analysis .305
$\mathrm{RR}(95 \% \mathrm{Cl}) \quad$ Weight
$\%$

\begin{tabular}{ccc}
\hline & & \\
\hline 305 & 1 & 3.27
\end{tabular}

\section{Figure 2}

The incidence of cholelithiasis between MetS and Non- MetS population. 
Study

ID

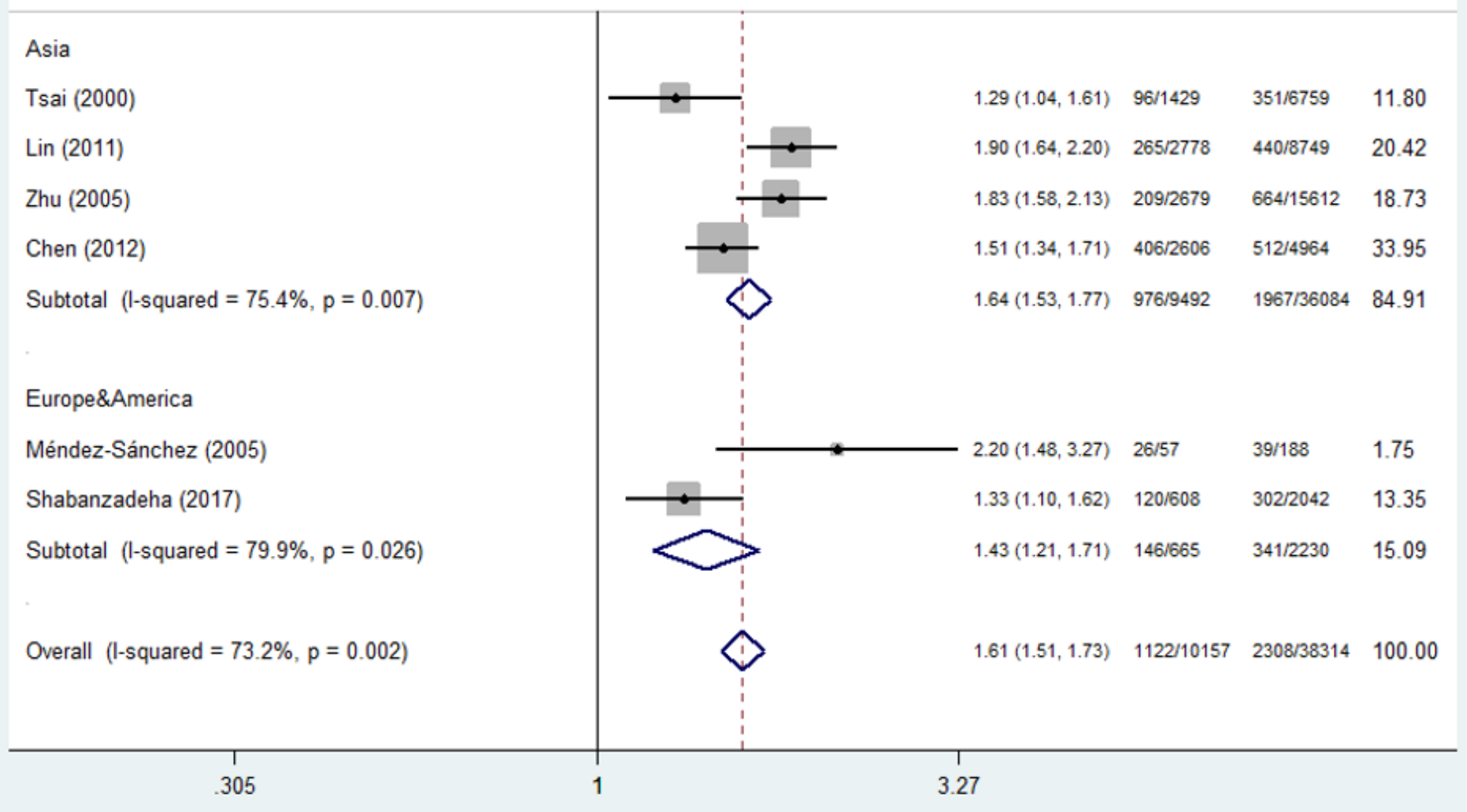

\section{Figure 3}

Subgroup Analysis By Region 
Study

ID

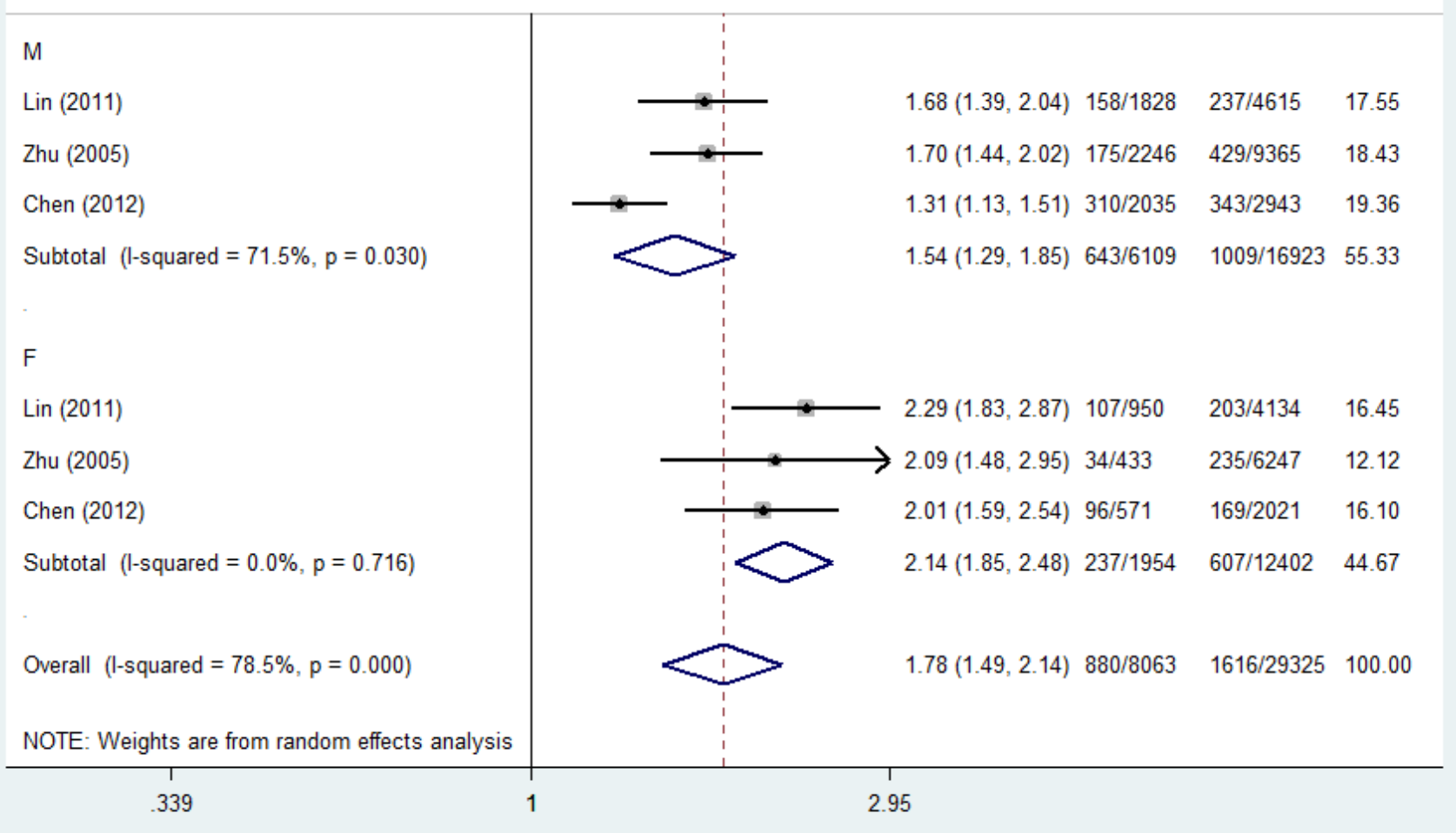

\section{Figure 4}

Gender on the incidence of GSD between MetS populations and non-MetS.

$\begin{array}{llll} & \text { Events, } & \text { Events, } & \% \\ \text { RR }(95 \% \mathrm{Cl}) & \text { Treatment } & \text { Control } & \text { Weight }\end{array}$

$1.70(1.44,2.02) \quad 175 / 2246 \quad 429 / 9365 \quad 18.43$

$1.31(1.13,1.51) 310 / 2035 \quad 343 / 2943 \quad 19.36$

$1.54(1.29,1.85) \quad 643 / 6109 \quad 1009 / 16923 \quad 55.33$

$2.09(1.48,2.95) \quad 34 / 433 \quad 235 / 6247 \quad 12.12$

$2.01(1.59,2.54) \quad 96 / 571 \quad 169 / 2021 \quad 16.10$

$2.14(1.85,2.48) \quad 237 / 1954 \quad 607 / 12402 \quad 44.67$

$1.78(1.49,2.14) 880 / 8063 \quad 1616 / 29325 \quad 100.00$

2.95 
Study

ID

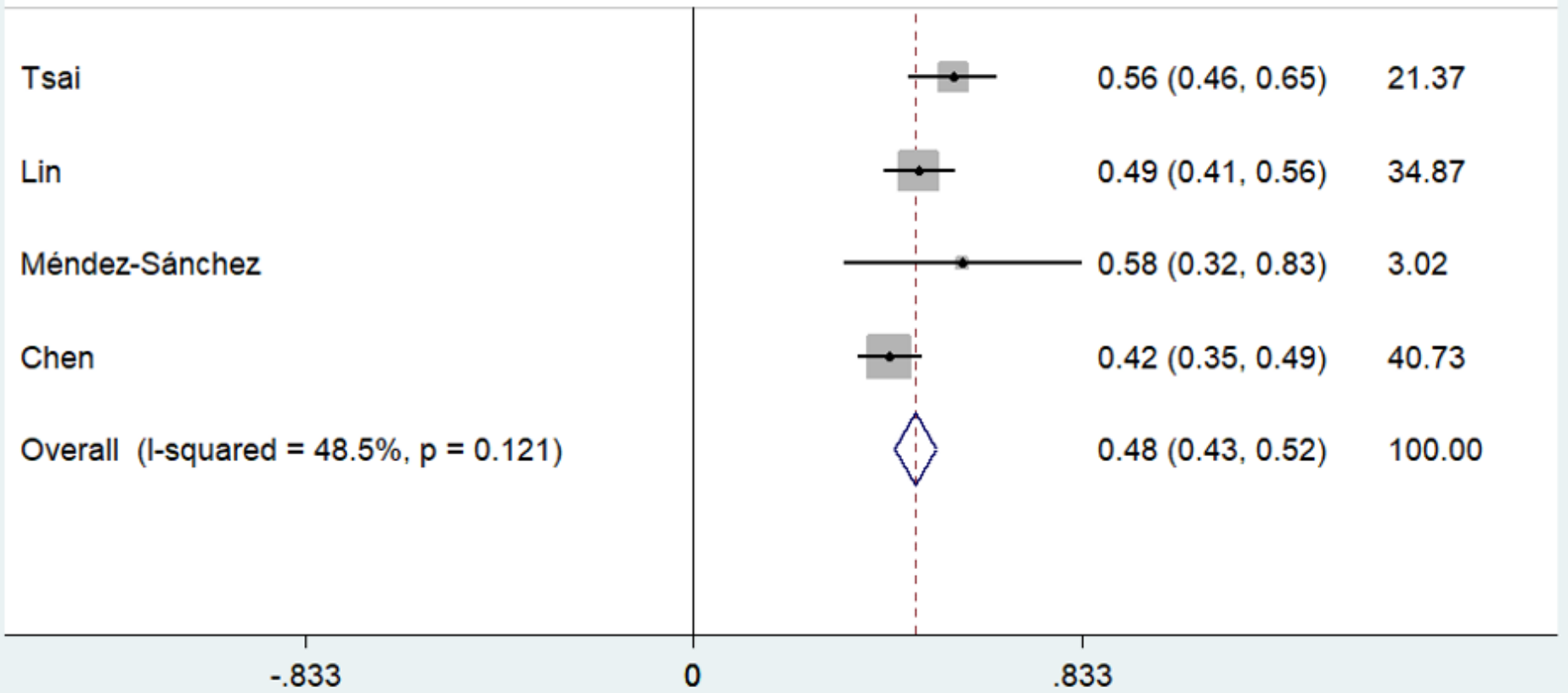

\section{Figure 5}

Age on the incidence of GSD between MetS populations and non-MetS. 
ID

$\operatorname{SMD}(95 \% \mathrm{Cl}) \quad$ Weight

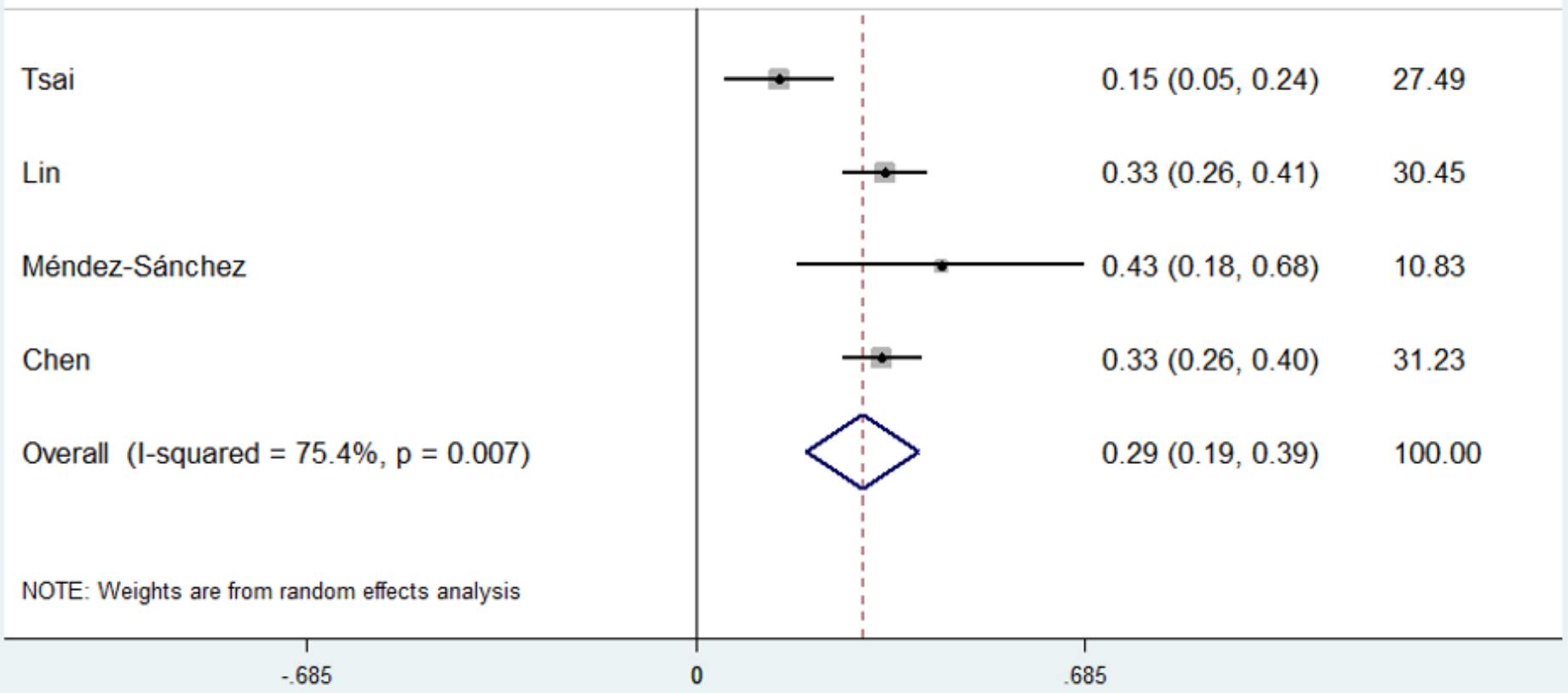

\section{Figure 6}

BMI on the incidence of GSD between MetS populations and non-MetS. 
ID

$\operatorname{SMD}(95 \% \mathrm{Cl}) \quad$ Weight

\begin{tabular}{|c|c|c|c|}
\hline Tsai & $\longrightarrow$ & $0.19(0.09,0.28)$ & 27.47 \\
\hline Lin & & $0.33(0.25,0.40)$ & 30.71 \\
\hline Méndez-Sánchez & & $0.53(0.28,0.78)$ & 10.27 \\
\hline Chen & & $0.36(0.29,0.43)$ & 31.56 \\
\hline Overall $(\mathrm{I}-$ squared $=73.3 \%, \mathrm{p}=0.011)$ & & $0.32(0.22,0.42)$ & 100.00 \\
\hline NOTE: Weights are from random effects analysis & & & \\
\hline
\end{tabular}

\section{Figure 7}

WC on the incidence of GSD between MetS populations and non-MetS. 
ID

$\operatorname{SMD}(95 \% \mathrm{Cl}) \quad$ Weight

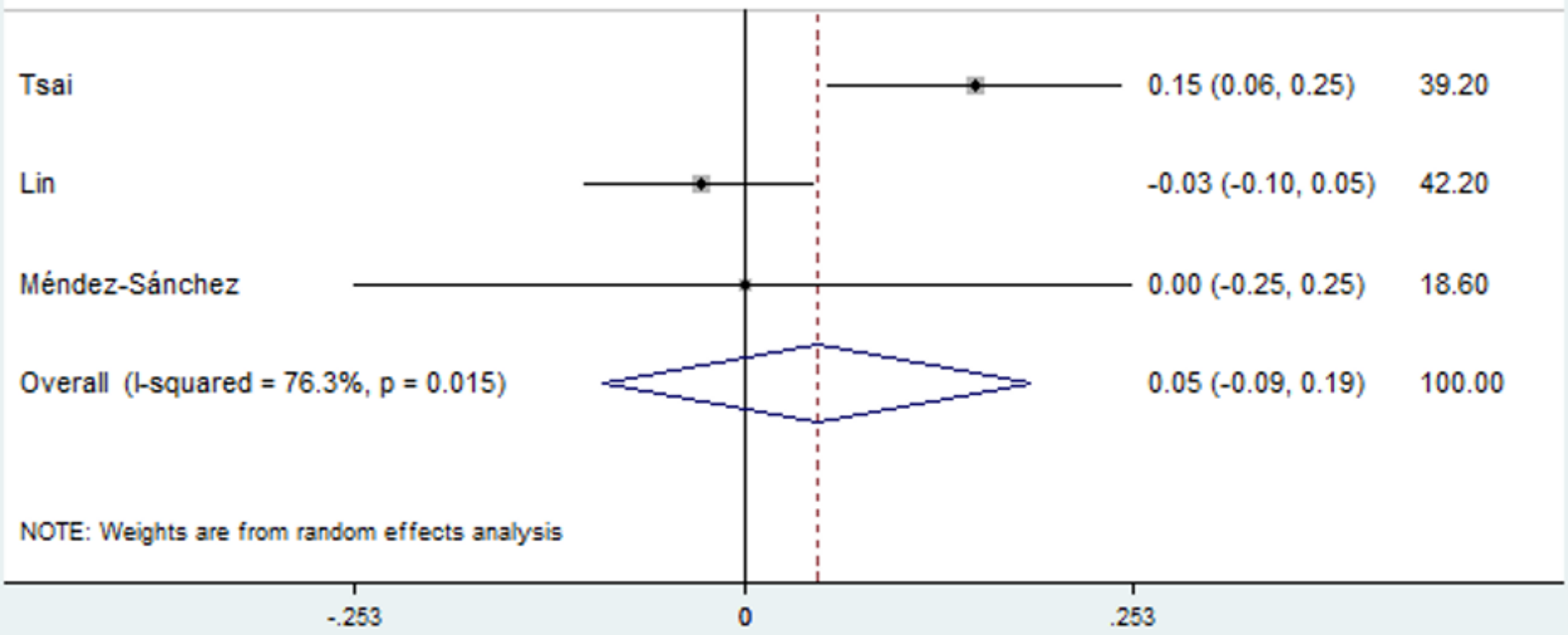

Figure 8

TC on the incidence of GSD between MetS populations and non-MetS. 
ID

SMD $(95 \% \mathrm{Cl}) \quad$ Weight

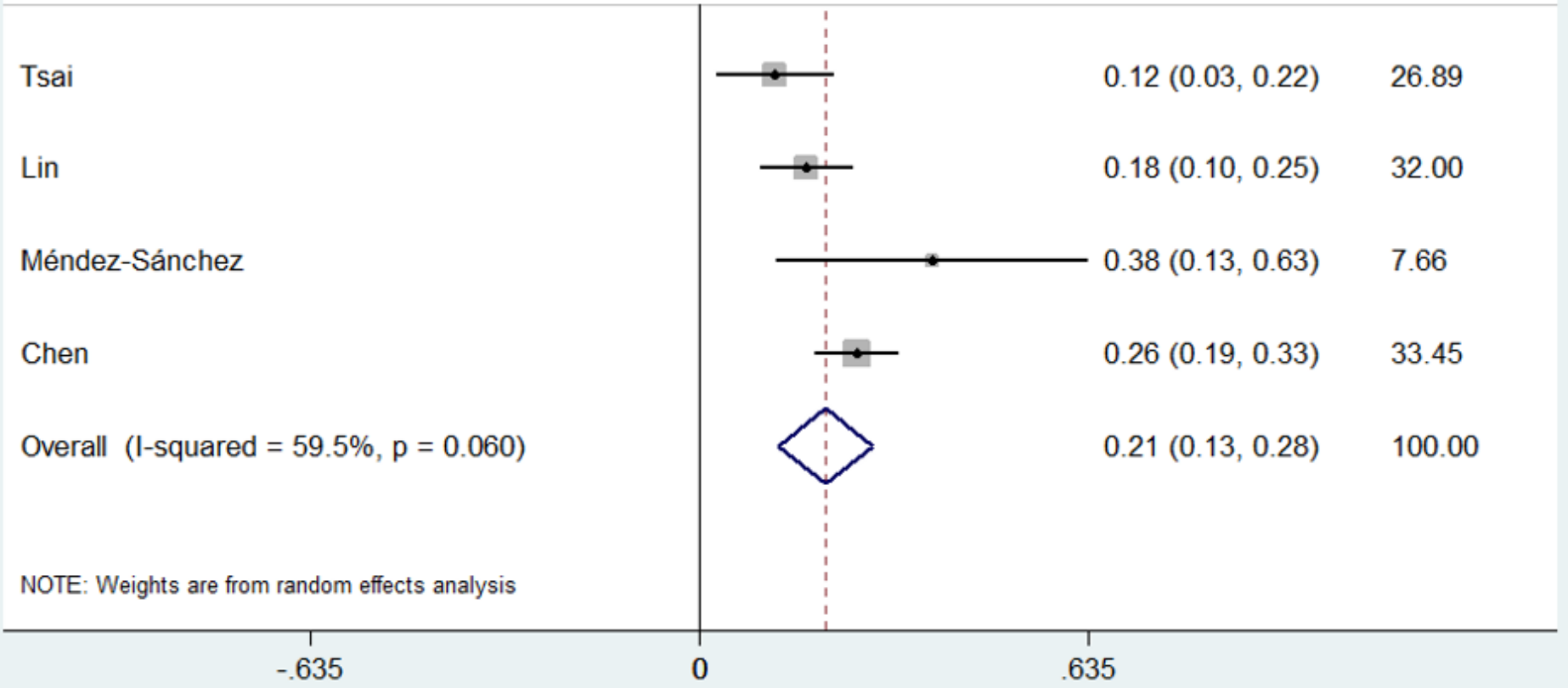

\section{Figure 9}

FPG on the incidence of GSD between MetS populations and non-MetS. 